\title{
ADMINISTRAÇÃO ESPECIFICACA
}

\section{O Administrador Público e as Pesquisas Sócio- econômicas nos Problemas da Vida Rural}

\author{
Rômulo CAvina
}

\section{CONSIDERAÇÕES INICIAIS}

S ABEmos que a consolidação do feito de CABRAL só foi possível aos portuguêses depois da gradativa dominação da terra de Santa Cruz pela agricultura ミ pela pecuária. A seguir, a audácia do bandeirante, a persistência do garimpeiro, a dura paciência do boiadeiro concluiram a posse e ampliaram a terra, levando longe a fronteira.

Dêsses esforços resultou a expansão geográfica para além do limite impôsto pela linha de Tordesilhas. Mais ainda: do uso da terra assim alargada veio o progresso econômico que financiou e financia a nossa existência de Nação.

E' da terra que nos vêm o alimento e o vestuário; o bem-estar e o luxo da população brasileira sãc pagos con: produtos da terra .

Usando os oito e meio milhões de quilômetros quadrados é que vivem Ino padrão de vida atual - os quase sessenta milhões de brasileiros. Tudo quanto temos foi pago com a venda de produtos extrativos, agrícolas e pecuários, obtidos com o trabalho, nem sempre satisfatòriamente recompensado, da. gente que vive no meio rural.

Se mantivermos esta parte da nossa população em atividade rendosa, sadia, trabalhadora, confiante e feliz, teremos reservas demográficas valiosas para completar a população urbana e a riqueza do país em. franco e seguro progresso. Para tanto é necessário, todavia, que a nossa administração esteja alertada para o objetivo fundamental, que conduza a gente do campo a viver melhor na terra que cultiva.

Nunca será demais acentuar a motivação, de que o administrador público tanto precisa, a fim de apreciar devidamente a contribuição dos fatos da vida rural para a economia do Brasil.

Cumpre, de fato, encarecer a importância dos problemas da vida rural nos quais o administrador público brasileiro deve concentrar especial atenção. Atualmente êste interêsse, longe do enfraquecer, cresce com a industrialização progressiva do país. Daí surgiren. novas dificuldades, pois cumpre que indústria e agricuitura, ao invés de se oporem, tendam a complementar-se. 
Nosso mercado interno tem enorme capacidade potencial para absorver slevada produção agríccla e variada produção industrial. Essa procura interna, na sua parte efetiva, atende à concorrência, à luta de preços e de qualidade, o que torna os problemas de produção sempre mais complicados para o produtor .racional.

\section{IMPORTÂNCIA DOS Trabalhos DE PESQUisas}

Bastaria a citação de dois fatos para ressaltar-se a importância da pesquisa, como preliminar à quase totalidade das medidas administrativas a serem tomadas em benefício do meio rural.

Antes de tudo, a escolha e a aplicação de tais medidas para resolver os problemas da vida rural exigem imprescindível e prévio conhecimento da realidade social brasileira. Êste conhecimento se impõe por dois motivos prinzipais:

a) porque essa realidade vem sendo esquecida e deturpada nas interpretações, quase sempre mal orientadas, e em geral nascidas nos gabinetes administrativos, dirigidos por políticos, guindados a êsses postos por fôrças exclusivamente político-partidárias;

b) porque ainda não se reconheceu que aquêle setor da vida brasileira - o meio rural - também progride e evolui em função das modificações sofridas pela realidade brasileira geral. A vida rural de hoje é diferente da de ontem, em atenção à propagação de inventos e dadas as facilidades que a rodovia e o caminhão, o rádio, a imprensa, o avião e a televisão vêm criando para a elevação cultural das populações do interior.

Tccio plano de ação - geral ou particular - para uma determinada área, deve ser precedido de suficientes estudos das condições e recursos do meio. $E^{\prime}$ 'indispensável a análise de dados regularmente coletados pelas repartições statísticas, os quais, depois de completados por novos elementos, obtidos diretamente pelos pesquisadories de cada problema devem ser por êstes minuciosamente ponderados e utilizados.

O conhecimento de todos os setores ligados ao problema a resolver também deverá ser detalhado e tão completo quanto necessário à sugestão e escotha das medidas que encaminhem e realizem a solução do problema em aprêço.

O conhecimento rigorosamente em dia das atividades, do comportamento, das maneiras de agir, de pensar, de sentir de uma população a ser beneficiada por determinada medida administrativa, terá de ser a base da atividade dos administradores. E' óbvio que inspirar legislação e baixar regulamentos su instruções em desacôrdo com a realidade social há de provocar choques a reaçöes dentro dos grupos sociais a que foram errôneamente destinados.

Por outro lado, a participação dos interessados nos debates preliminares. na discussão dos projetos a no traçado dos planos, dará maior conteúdo e másima eficiência às atividades dos dirigentes.

Uma das características de nossa economia são as rápidas e complexas mudanças por que vem passando, em virtude de ser tão diferente o meio em que irão aplicar-se soluções e experiências que outros povos vêm conhecendo. 
Por isso, copiar, pura e simplesmente, o que se fêz alhures, sem adaptações baseadas no conhecimento dessa realidade social, é perda de tempo precioso $\epsilon$ de grandes esforços.

A pesquisa e a observação atenta dos fatos proporcionarão ao administradcr uma posição objetiva em face da realidade sócio-econômica e lhe permitirão examinar as providências mais adequadas. Administrador sem acuidade para o valor da pesquisa é administrador condenado a não ver frutificar suas nelhores intenções.

A pesquisa orienta, retifica, sustenta, prepara novas opiniões. Afasta preconceitos, destrói idéias preestabelecidas, excessivamente teóricas e generalizadas, algumas vêzes erradas. A pesquisa confere pela medida dos fatcs, pela anotação metódica dos conhecimentos, um sentido de realidade a quem não o tinha ou não sabia utilizá-lo.

E' preciso ressaltar que um pesquisador não se encomenda nem se improvisa. Ao lado de características pessoais determinadas, é evidentemente necessária uma cultura adequada e uma preparação bem dirigida.

\section{Formação de Pessoal para os Problemas RuRais}

Uma preparação especializada se evidencia indispensável à formação do administrador públicc brasileiro para tratar dos problemas rurais. E' claro que aos engenheiros agrônomos e médicos-veterinários, caberá a maior parcela Jêsses esforços e responsabilidade; outras especializações surgirão, depois, espon:âneamente, como a de economista rural. São imprescindíveis, todavia, auxiliares quaiificados que possam complementar a atividade daqueles profissionais, notadamente no setor administrativo pròpriamente dito.

Para a formação de engenheiros agrônomos e rédiccs-veterinários existem atualmente, no país, doze escolas superiores de Agronomia e oito de Veterinária. Sua freqüência, no entanto, é reduzida, dado o grave êrro de subestimação dos serviços que os seus profissionais prestam, percebendo mesmo os ocupantes das duas carreiras, tanto no serviço público federal como estadual, remuneração inferior à dos demais profissionais de nível universitário.

Além disso, o derrotismo do "sendo nacional" que se opõe a "em país civilizadc é assim" - é um preconceito que leva a admitir não possuirmos capacidade criadora, o que se torna justificativa para atitudes displicentes, que não nos absolvem, nem nos eximem das responsabilidades sociais que pesam sôbre um de nós comc membro da comunidade brasileira.

Torna-se, pois, fundamental que o administrador não se entregue a extremos individualistas, não se alheie do grupo nem da realidade social ambiente. Sua função não é isolada, antes solitária com tantas outras, pois se ninguém pode viver sòzinho no mundo, muito menos pode pretender resolver sòzinho problemas próprios de grupos. Se nos alhearmos, como administradores, com isso não nos furtaremos à responsabilidade pelos erros a que induziremos a sociedade que em nós confia e espera.

Por outro lado, apenas agora, dada a premência econômica que algumas regiões brasileiras vêm enfrentando, é que êsses profissionais vêm sendo pro- 
zurados por emprêsas particulares e solicitadas por outras atividades que não as do Ministério ou das Secretarias de Agricultura, atenuando-se, assim, o aspecto socializado fundamental anteriormente único.

Esta oportunidade torna-se a mais adequada para uma sugestão: as Escolas de Agronomia e Veterinária precisami divulgar, entre os estudantes secundários, com o fim de despertar e aproveitar vocações, as oportunidades que lhes oferecem e as características e vantagens das profissões a cujo iexercício habilitam.

No que se refere ao pesscal administrativo pròpriamente dito, haveria a recomendar a sua especialização nas modernas técnicas de administração de pessoal, material e demais atividades-meios.

Neste caso, os cursos do D.A.S.P. e, particularmente, a Escola Brasileira de Administração Pública da Fundação Getúlio Vargas estão chamados a cumprir uma tarefa destacada.

\section{Roteiro PARA AS PESQuisas Sócio-Econômicas}

Para que 0 administrador possa escolher e indicar a medida ou a providência mais adequada à solução de um dado problema da vida rural, é necessário, como já dissemos, conhecimento prévio do meio ao qual a mesma medida se destinará.

A pesquisa permitirá observar os fatos e trará os dados para que o administrador imagine uma explicação, ou melhor, formule uma hipótese. Criticada e verificada essa hipótese, apcntará, em conseqüência dos resultados de sua análise, a solução mais adequada.

Para orientar o trabalho, apresentamos, a seguir, um projeto de roteiro para pesquisas sócio-econômicas destinadas a incaminhar a solução de problerrias da vida rural:

1. Sentido do plano - Trata-se, por exemplo, de planejar um estudo de campo preliminar, que deve ser associado a outro levantamento indireto, feito no Rio, a fim de organizar os dados necessários ao conhecimento de um município ou de uma região. O exame dos dados recolhidos servirá de orientação à repartição central para o estabelecimento de seus serviçcs locais.

2. Objetivo - Se o município a ser estudado possuir características. peculiares e próprias, o levantamento será tanto mais indispensável para as decisões da referida repartição.

As famílias rurais localizadas no município em questão, desfrutando de serviços de Educação, Saúde, Recreação, Religião, Agricultura e Cooperativas, serão relacionadas com os caracteres e funcionamento de tais serviços, que retratam o bem-estar alcançado pela comunidade. Sabe-se, todavia, que os contatos das famílias rurais com êsses serviços, e dêstes com aquelas, revelam falhas; daí ser conveniente cibservar a falta de segurança para a família e de satisfação ou interêsse pelo trabalho. Conhecida e caracterizada a relação família-serviços, será possível escolher a assistência a ser prestada, orientação a ser sugerida, a fim de elevar o bem-estar local por meio de maior eficiência nêsses serviços. 
O segundo objetivo da pesquisa é, ainda, c de servir de base ao prosseguimento dos estudos, mais profundos e particularizados, que a repartição central venha a fazer após o estabelecimento de sua agência local.

3. Quadros de referência - As relações sócio-econômicas a serem observadas ocorren;, diferentemente, nos quadros rurais e urbançs do município e em função das classes ocupacionais. Assim, seja rural ou urbana, cumpre observar a família em função de sua classe.

4. Delimitação do universo - O universo em que se situará a pesquisa precisa ser rigorosamente definido, devendo a escolha do município preferido obedecer principalmente à:

$\left.1^{\circ}\right)$ proporção da população rural com a urbana;

2..$\left.^{\circ}\right)$ proporção dos produtos agrícolas fornecidos ao mercado local e aos demais com os quais o município estiver ligado.

5. Hipóteses - São as seguintes:

a) ausência ou presença de entidades que se preocupem com os serviços acima indicados;

b) eficiência e capacidade dessas entidades relativamente ao meio; e

c) relações dos serviços caracterìsticamente municipais, com o objetivc de orientar e medir a atividade a ser exercida pela agência local da repartição interessada.

6. Unidades - A pesquisa será realizada em número determinado de municípios, em conformidade com os recursos materiais e de pessoal.

7. Instrumentos - $\mathrm{O}$ estudo dos serviços será feitc por meio de roteiros descritivos. Sua ,eficiência e relações com as famílias rurais será comprovada através dos questionários enviados às famílias rurais escolhidas por amostragem.

8. Preparação dos instrumentos - O pessoal será prèviamente orientado; a atividade no Rio e no município será planejada, com a divisão de tarefas e a respectiva coordenação. Convirá prever o orçamento, o serviço de transporte, o alojamento e o material necessário.

9. Execução dos serviços de pesquisa - A equipe organizada visitará o município escolhido em um levantamento preliminar e, em seguida, para pesquisa pròpriamente dita. Convém prever visitas sucessivas para correções ulteriores.

10. Análise dos dados - Recolhido o material da pesquisa, será, em seguida, criticado e analisado. Serão preparados quadros para responder às perguntas formuladas nas hipóteses de trabalho e nos questionários.

11. Relatório - O relatório final da pesquisa será descritivo e baseado nos dados da observação de campo e de escritório. Dará informes e números e não decisões. Será uma exposição, não conterá propostas.

12. Conclusão - À base do relatório a repartição central decidirá da instalação da agência local que terá a seu cargo, inclusive, a continuação de pesquisas parciais e mais profundas, sob o plano a ser traçado em função das características específicas do município em estudo. 